\title{
Construcción y transformación del riesgo tecnológico: la terminal de combustibles El Beaterio-Quito
}

Construction et transformation du risque technologique : le centre de stockage de combustibles du Beaterio (Quito)

Construction and transformation of the technological hazard: El Beaterio (Quito) fuel storage facility

\section{Jairo Estacio}

\section{OpenEdition} Journals

Edición electrónica

URL: http://journals.openedition.org/bifea/2381

DOI: 10.4000/bifea.2381

ISSN: 2076-5827

\section{Editor}

Institut Français d'Études Andines

\section{Edición impresa}

Fecha de publicación: 1 diciembre 2009

Paginación: 683-707

ISSN: 0303-7495

Referencia electrónica

Jairo Estacio, «Construcción y transformación del riesgo tecnológico: la terminal de combustibles El Beaterio-Quito », Bulletin de l'Institut français d'études andines [En línea], 38 (3) | 2009, Publicado el 01 junio 2010, consultado el 17 noviembre 2020. URL : http://journals.openedition.org/bifea/2381 ; DOI https://doi.org/10.4000/bifea.2381

Les contenus du Bulletin de l'Institut français d'études andines sont mis à disposition selon les termes de la licence Creative Commons Attribution - Pas d'Utilisation Commerciale - Pas de Modification 4.0 International. 


\title{
Construcción y transformación del riesgo tecnológico: la terminal de combustibles El Beaterio-Quito
}

\author{
Jairo Estacio*
}

\begin{abstract}
Resumen
Las instalaciones de almacenamiento de combustibles de la terminal El Beaterio representan intereses económicos a escala local (Distrito Metropolitano de Quito) y nacional (el Ecuador) y, a la vez, constituyen fuentes de peligro para la población localizada a su alrededor. La exposición de la población a peligros potenciales no responde simplemente a factores sociales de localización, sino que están relacionados con políticas de planificación urbana adoptadas en diferentes administraciones municipales. En primera instancia se reforzó la consolidación urbana sin considerar el riesgo que representaban estas instalaciones. Tras evidenciarse el peligro a través de pequeños incidentes suscitados en la terminal y la emanación de fuertes olores a combustible, se cambió la percepción del riesgo por parte de la población y de la municipalidad. Este cambio de percepción permitió la generación de herramientas de gestión del riesgo a través de modelos de simulación de la amenaza tecnológica de un lado y de la planificación urbana de otro. La delimitación de zonas de protección y amortiguamiento, donde existían asentamientos humanos ya consolidados, llevó a un conflicto de uso de suelo y a un proceso de lucha entre actores institucionales y poblacionales para desplazar las instalaciones hacia un sitio más seguro. En este contexto, la política de reducción de una parte de la amenaza tecnológica (desplazamiento del Gas Licuado de Petróleo), considerada como la de mayor peligro, aumentó la vulnerabilidad de la población, debido a un nuevo cambio de percepción del peligro y al crecimiento de la población en zonas anteriormente consideradas de amortiguamiento. Por lo tanto, el riesgo tecnológico en El Beaterio «se crea y se transforma», revelando la incertidumbre existente por parte de las autoridades locales en su intento por reducirlos.
\end{abstract}

Palabras clave: riesgo tecnológico, vulnerabilidad, espacios de riesgo, percepción de riesgos, planificación urbana, uso de suelo, explosión, GLP, Quito

* Laboratorio Edytem, Département de Géographie, Université de Savoie, Chambéry, France. E-mail: jairo.estacio@univ-savoie.fr. 


\title{
Construction et transformation du risque technologique : le centre de stockage de combustibles du Beaterio (Quito)
}

\begin{abstract}
Résumé
Le centre de stockage de combustibles du Beaterio est d'un grand intérêt économique à l'échelle locale (district métropolitain de Quito) et nationale (Équateur). Il constitue en même temps une source de danger pour la population installée à proximité. L'exposition de la population à ce danger n'est pas seulement liée à des facteurs sociaux de localisation mais aussi aux politiques de planification urbaine menées par différentes administrations municipales. Dans un premier temps, la consolidation urbaine a été favorisée sans que le risque ne soit pris en compte. À la suite d'incidents survenus dans le centre de stockage et l'émanation de fortes odeurs, la perception du risque par la population et par la municipalité s'est modifiée. Cette transformation s'est concrétisée par la mise au point d'outils de gestion du risque sous l'angle de la simulation de l'aléa technologique et de la planification urbaine. La délimitation des zones de protection et d'amortissement dans des secteurs déjà urbanisés a engendré un conflit entre les institutions et la population dont l'enjeu était le déplacement des installations vers des zones plus sûres. Dans ce contexte, la réduction de l'aléa technologique (déplacement du Gaz de Pétrole Liquéfié), considéré comme le plus dangeureux, a accru la vulnérabilité de la population en raison d'un changement de perception du risque et de l'augmentation du nombre d'habitants dans les anciennes zones d'amortissement. C'est ainsi que se crée et se transforme le risque technologique lié au Beaterio, mettant en évidence une certaine impuissance des autorités locales à la réduire.
\end{abstract}

Mots clés : risque technologique, vulnérabilité, espaces à risque, perception des risques, planification urbaine, utilisation du sol, explosion, GPL, Quito

\section{Construction and transformation of the technological hazard: $\mathrm{EI}$ Beaterio (Quito) fuel storage facility}

\section{Summary}

El Beaterio fuel storage facility represents an economical interest in both the local (Quito Metropolitan District) and national (Ecuador) scale. At the same time, this facility constitutes a present threat to the surrounding community. The community's exposure to potential threats does not respond to social location factors alone, but is also related to municipal urban planning policies adopted during different municipal administrations. Firstly, these administrations conducted an urban consolidation that does not account for the threat that these facilities pose. Once the danger became evident through a series of minor events at the fuel storage facility as well as fuel smell in the air, a transformation of hazard perception was implemented by both the community and the municipality. This change in hazard perception allowed the creation of hazard control tools using technological hazard simulation models and urban planning.

Setting boundaries in protection areas and buffer zones where human settlements were established lead to land conflict and a struggle between institutions and population. The main issue was the relocation of the facilities on a safer place. In this context, the policy of reducing a part of the technological hazard (liquefied petroleum gas), which was considered the most dangerous, finally increased the vulnerability of the population. This vulnerability is due to another change in hazard perception and also to the population's growth affecting zones that were previously considered buffer zones. Therefore, El Beaterio technological hazard obeys a «creation and transformation» dynamic that shows the current local authorities uncertainty over the reduction of the aforementioned hazards.

Key Words: Technological hazard, vulnerability, hazard zones, hazard perception, urban planning, land use, explosion, LPG, Quito 


\section{INTRODUCCIÓN}

Si bien los estudios relacionados con la presencia de peligro en lugares urbanos no son nuevos en el Ecuador, sí lo son los estudios de riesgos tecnológicos y las implicancias territoriales relativas a su manejo y reducción. En el DMQ las industrias denominadas de alto impacto y peligrosas (industrias que manejan material químico peligroso e hidrocarburífero) están repartidas particularmente en el sur y en el Valle de Los Chillos (Zona Itulcachi). Una proporción importante de estas industrias están relacionadas con el almacenamiento y transporte de combustibles, cuyo punto nodal se localiza en el sector de El Beaterio, al sur de la ciudad de Quito (ver fig. 1).

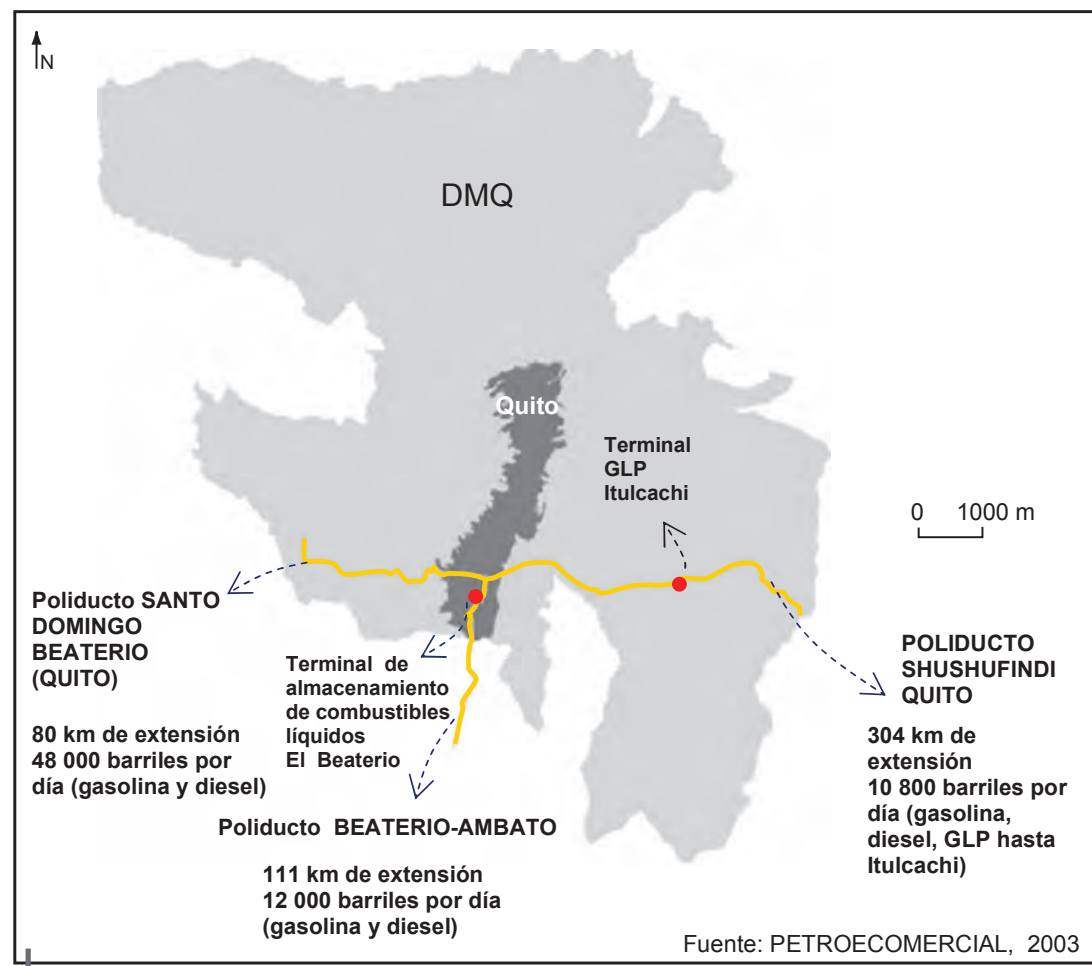

Figura 1 - Localización de los elementos de abastecimiento y transporte de combustibles en el DMQ

¿Cómo se construyen y transforman los espacios de riesgo tecnológico en El Beaterio? ¿Cuáles son los factores políticos, jurídicos y sociales que contribuyen a su aparición? Son cuestiones que se intentan abordar en el presente artículo. En efecto, la conformación de los espacios de riesgo en las instalaciones de El Beaterio es, por un lado, consecuencia de las diferentes formas de planificación y manejo de las industrias peligrosas y, por otro, producto de las formas de asentamiento poblacional y su percepción y gestión del riesgo tecnológico. 
Las decisiones locales sobre el manejo de instalaciones de El Beaterio demuestran diferentes tipos de percepción de las autoridades municipales sobre el riesgo engendrado a través del tiempo. El riesgo tecnológico, en una primera instancia, es desconocido o poco percibido, pero después pasa a ser considerado y gestionado principalmente a través de la simulación de la amenaza tecnológica, que permite optar por medidas políticas y jurídico territoriales. No obstante, el crecimiento urbano paulatino alrededor de las instalaciones sigue en aumento y muy poco se ha podido hacer para controlarlo. Al contrario, el Municipio, a través de los documentos de planificación de las sucesivas administraciones municipales, mantuvo la vocación urbana de la zona. Por lo tanto, cabe la pregunta: ¿son suficientes las medidas jurídico territoriales adoptadas para el control de riesgo y la mejora de las condiciones de habitabilidad en la zona? Esta cuestión supone una reflexión posterior sobre el grado de incertidumbre de estas medidas y el control de los escenarios de riesgo tecnológico.

En este contexto, el presente artículo aborda en primer lugar las etapas de construcción del riesgo tecnológico en El Beaterio a través de un análisis espacio temporal de los usos de suelo en diferentes periodos de tiempo, en relación con las diferentes políticas de planificación territorial y las medidas jurídico territoriales para controlar el riesgo. En segunda instancia, se intenta abordar algunas reflexiones sobre las limitaciones e incertidumbres de las medidas adoptadas para controlar el riesgo tecnológico en El Beaterio.

\section{LAS ETAPAS DE CONSTRUCCIÓN DEL RIESGO TECNOLÓGICO EN LA ZONA DE EL BEATERIO}

\section{1. La retrospectiva de la zona El Beaterio: un sector rural por excelencia}

Si bien las actividades hidrocarburíferas en el Ecuador existen desde inicios del siglo XX, la actividad económica predominante era la agricultura, desarrollada comúnmente en la periferia de las ciudades. En las décadas de 1950 y 1960 la zona de El Beaterio se constituía como parte de la periferia de Quito, donde el uso del suelo era principalmente agrícola, estructurado en grandes haciendas (ver fig. 2). Incluso, en el Plan Director de Quito emprendido en el año 1967, esta zona consta como rural y aún no era integrada dentro de los planes de ordenamiento urbano. En aquella época, la zona de El Beaterio, la vía Panamericana Sur y la vía férrea representaban hitos históricos importantes, cuyo rol será decisivo en el crecimiento urbano, en la movilidad comercial de productos agrícolas y en la conectividad de varias haciendas importantes de la región que posteriormente se convertirían en cabeceras parroquiales (Enriquez, 2005).

En consecuencia, el uso real de la zona correspondía a un uso agrícola de grandes parcelas, la misma que coincide con el uso planificado (ver corema expresado en la figura 2). En los años 1970, cuando la actividad hidrocarburífera comienza 


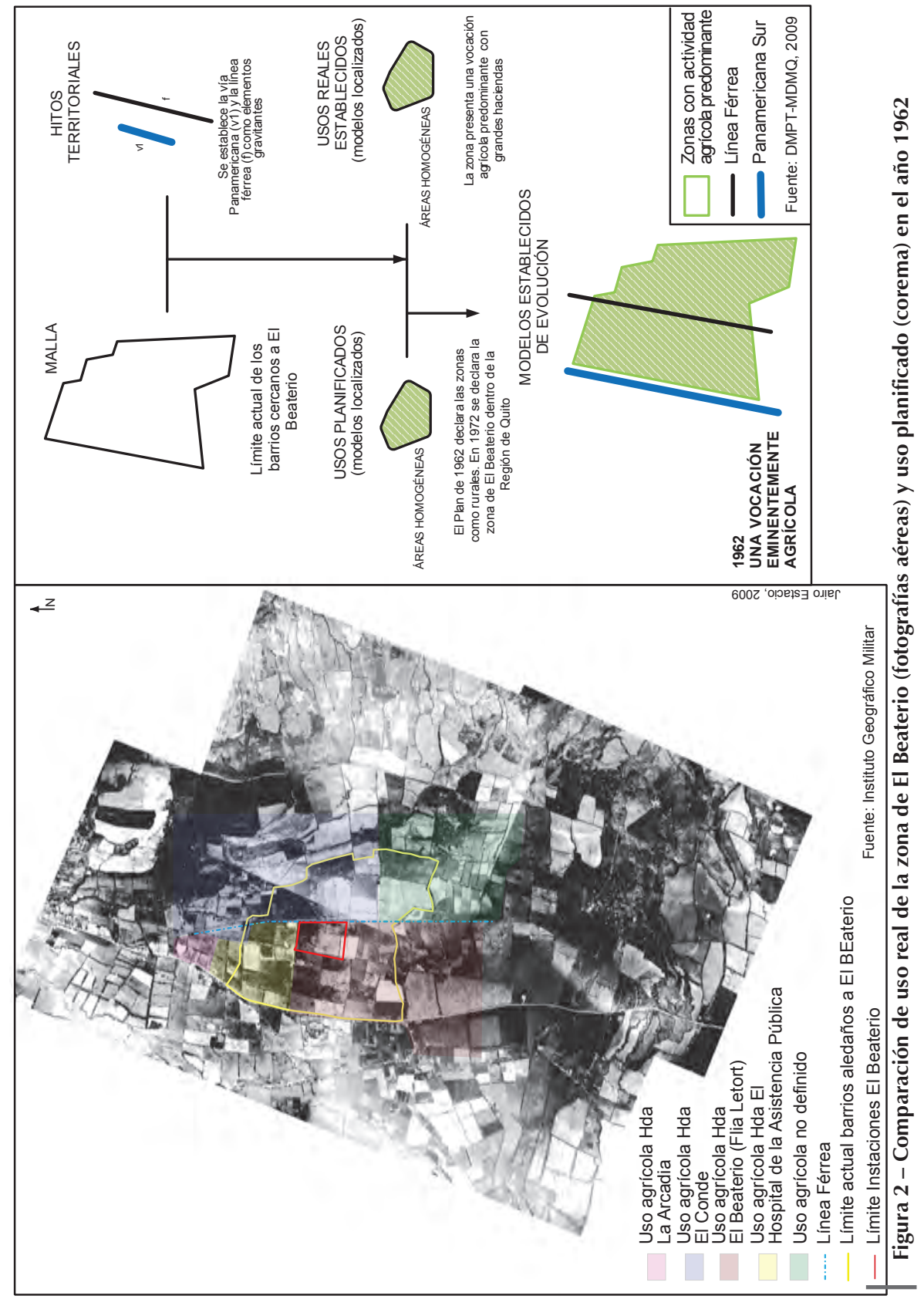


a desarrollarse, se instalan los primeros tanques de almacenamiento de menor escala en el sector de San Bartolo, conjuntamente con un poliducto denominado Durán-Quito. El poliducto conecta la refinería de La Libertad (localizada en la Costa Ecuatoriana) con la ciudad de Quito. En esta década aparece la noción de regionalización de la ciudad (Propuesta Regional Quito de 1973) en la cual El Beaterio forma parte de la Región Quito, pero no se establecen usos definidos más allá de áreas verdes, aún cuando su uso era agrícola (Municipio de Quito, 1974).

En 1975 tras el boom petrolero, se inicia la construcción de la Terminal de Productos limpios El Beaterio en una zona de haciendas. El Beaterio constituye en sí mismo el hito del desarrollo petrolero y representa un punto estratégico para la provisión de combustible (gasolina, diesel, jet fuel y GLP) hacia el centro y norte del país. Con la proximidad de la línea férrea y la presencia del poliducto Duran-Quito la zona presenta ventajas de localización, pues son alternativas para el transporte de combustibles. A principios de la década de 1980, con la ampliación de la terminal con tanques de mayor capacidad y la construcción del poliducto Santo DomingoQuito y el poliducto Shushufindi-Quito, se consolida una de las más importantes instalaciones estratégicas de abastecimiento del país.

\section{2. La construcción de los escenarios de riesgo tecnológico: primeras políticas adoptadas}

En los años 1980 la zona de El Beaterio se encuentra oficialmente dentro de los límites de la denominada «Área Metropolitana de Quito» (AMQ). Esta vinculación permite a la Municipalidad adoptar diferentes formas de manejo de la zona, cuyas primeras medidas de planificación coadyuvarían a la generación de espacios de riesgo en El Beaterio. En efecto, las políticas de planificación generadas en esos años consideran la expansión urbana del sur de Quito y de los valles como una estrategia para controlar jurídicamente los espacios urbanos que presentan una ocupación desordenada y en crecimiento. En tal virtud, los espacios especialmente localizados al occidente de la zona industrial de El Beaterio (consideración espacial de las instalaciones de El Beaterio para la década de 1980) son considerados como zonas de expansión urbana. Estas medidas citadas en los documentos de planificación como el Plan Quito (1980)1 y la ordenanza 2446 (1985)2 demuestran el interés de la municipalidad por controlar estos espacios bajo un esquema expansionista3 y a la vez articulador del área metropolitana (Perez 1984).

1 Si bien en el Plan Quito no se enmarcó en una estructura jurídica para su aplicación, es un documento que expresa la visión del desarrollo urbano y la acción municipal de la época.

2 Este documento jurídico muestra de manera oficial el Área Metropolitana de Quito para incluir algunas parroquias rurales adicionales, en un intento por ponerlas bajo control municipal.

3 Este término expresa la visión de incorporación y de consolidación urbana definida en las herramientas de planificación y uso de la época. Con esta visión se intenta buscar nuevos espacios urbanos frente a una creciente demanda relacionada con el crecimiento de la población y el surgimiento de asentamientos ilegales. 
La visión expansionista de la ciudad demuestra la ausencia de percepción de la problemática de riesgos tecnológicos por parte de las autoridades locales, debido al insuficiente conocimiento sobre las fuentes de peligro y sus consecuencias potenciales. La carencia de argumentos técnicos para clasificar las industrias por sus potenciales impactos tecnológicos permite delimitar zonas industriales de manera muy general (ver clasificación de industrias en la figura 3). De esta forma, la visión expansionista en El Beaterio contribuyó a la urbanización de la zona, aunque en principio de forma ilegal. Las grandes haciendas del sector de El Beaterio fueron lotizadas para la venta sin la regularización de escrituras individuales. Los primeros barrios que comenzaron a consolidarse alrededor de las instalaciones fueron El Conde, Argentina, Caupicho 1 y 2, Francisco Méndez y San Blas I.

A nivel nacional, las crisis económicas en los años 1980 motivan y refuerzan acciones estatales en pro de la actividad industrial como una estrategia de reactivación económica 4 . Esta visión desarrollista5 de la industria como fuente económica y de empleo constituye un punto de referencia adoptado por la Municipalidad de Quito, cuyas políticas empujan el desarrollo de la actividad industrial no solo hacia el sur de Quito sino en el norte y en los valles del AMQ (Plan Quito, 1980).

Así, desde su origen, El Beaterio es percibido más bajo una visión desarrollista relacionada con su rol económico y estratégico, que bajo una visión de riesgo. A partir del impulso de la actividad industrial — por la necesidad del uso de combustibles_-, el interés económico hacia las instalaciones se incrementa y se generan lazos de dependencia hacia varios sectores de la economía local y nacional. Asimismo, las instalaciones de El Beaterio presentan en su conjunto el funcionamiento de poliductos y gasoductos que forman parte del hito de desarrollo industrial nacional y local. Esto explica la ausencia de políticas de planificación preventiva y la carencia de normativa específica para el funcionamiento de industrias de alto impacto. Muy al contrario, las políticas urbanas alrededor de las instalaciones favorecen más bien la consolidación urbana y las actividades comerciales como criterio de integración de la actividad industrial y las dinámicas urbanas.

Tanto la visión expansionista como desarrollista sobre las instalaciones de El Beaterio demostradas en el Plan Quito generaron una concepción de este espacio donde el riesgo tecnológico era poco percibido por las autoridades correspondientes.

Sin embargo, las políticas de expansión urbana de la zona no fueron el único elemento que contribuyó al surgimiento de los asentamientos humanos en el sector Beaterio, sino la construcción de infraestructuras viales, consideradas hitos en el desarrollo urbano y ejes de atracción para asentamientos humanos y actividades comerciales. En la figura 3 se puede apreciar que las manchas de crecimiento urbano se desarrollan puntualmente a lo largo de la vía Panamericana Sur y de la vía de entrada a El Beaterio.

4 Muestra de ello es la Ley de Fomento Industrial o de Hidrocarburos adoptada a finales de la década de 1970.

5 Se relaciona netamente con la visión de desarrollo económico, la misma que muchas veces carece de otros componentes como factores sociales o ambientales. 


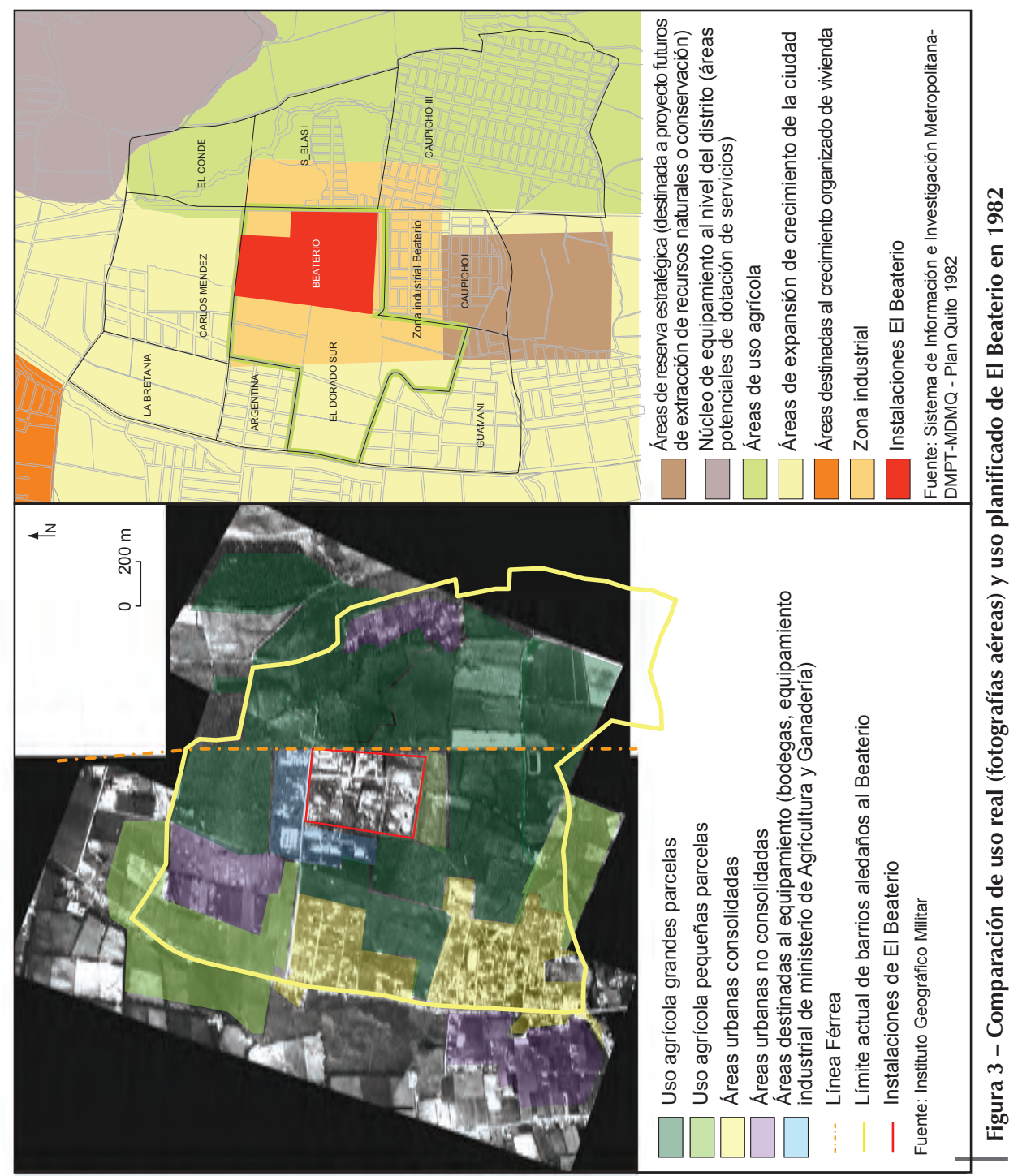


En la figura 4 resaltan las políticas de planificación adoptadas (Plan Quito 1981) en contraste con el uso real de la época. De esta forma se ha definido un modelo (corema) donde se pueden observar los sitios de mayor proyección de crecimiento y varios hitos territoriales como las vías y la línea férrea aledaña a las instalaciones, que representan ejes de atracción poblacional, denotando diferencias de uso alrededor de las instalaciones de El Beaterio. La construcción de este modelo se basó en leyes de la estructura y organización del territorio (Brunet, 2000) definidos en zonas de expansión y de evolución urbana y de heterogeneidad de usos, así como ejes de atracción y aparentes disimetrías enfocadas sobre todo en la localización diferenciada de asentamientos humanos.

En términos territoriales la zona de expansión urbana al oeste de las instalaciones (en amarillo) representa una forma de planificar los espacios de riesgos considerando además los ejes viales presentes. Esto causa un contraste en el territorio caracterizado por una ruptura en los usos reales y planificados. En efecto

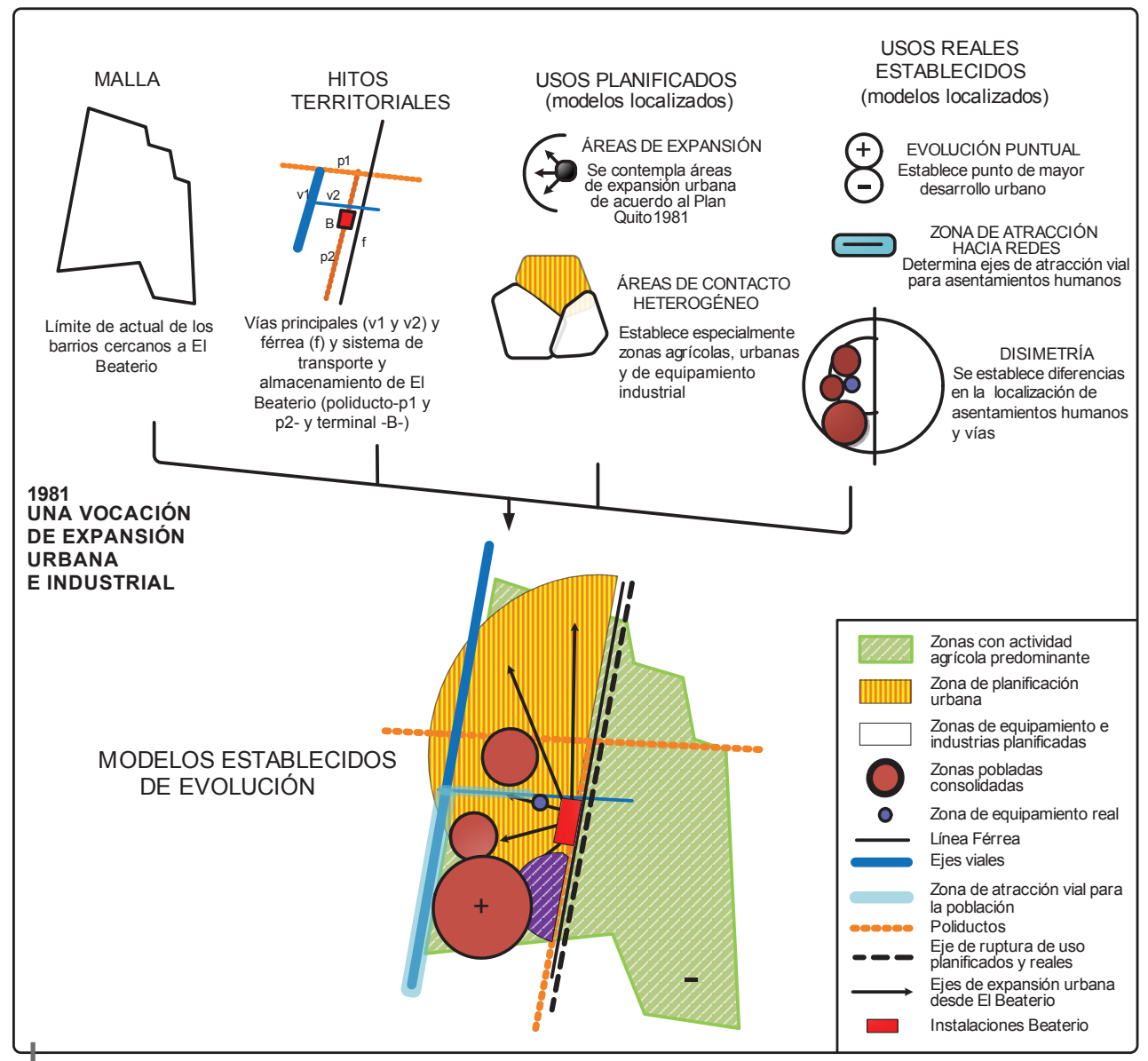

Figura 4 - Corema sobre la estructura urbana del sector de El Beaterio en 1981-1982 
al inicio de los años 1980, el oriente de El Beaterio era considerado como una zona aún agrícola y el occidente, como una zona de mayor desarrollo urbano.

\section{3. El cambio de mentalidad en vías de controlar el riesgo tecnológico: medidas político jurídicas adoptadas}

Hasta finales de la década de 1980 la zona de El Beaterio no representó para las autoridades y la población un mayor peligro potencial. No obstante, a principios de la década de 1990, se nota un cambio de representación por parte de las autoridades y de la población acerca de la zona, con un inicio del reconocimiento del peligro planteado por las instalaciones localizadas en el Beaterio. Los motivos que han provocado este cambio se pueden resumir de acuerdo a dos consideraciones:

- La presencia de un incendio de menor escala al interior de las instalaciones en el año 1988. Este evento de baja intensidad atrajo la atención de la opinión pública y de las autoridades sobre la posibilidad de eventos mayores.

- La presencia constante de olores de GLP y gasolina, producto de las actividades cotidianas o pequeños derrames controlados al interior de las instalaciones, son percibidos a cientos de metros a la redonda por una población en crecimiento, suponiendo problemas de salud y un alto impacto en la noción de peligro de la zona6.

Estos dos aspectos causaron (en una primera instancia) un cambio de percepción de El Beaterio, ya no solo como fuente económica (visión desarrollista), sino como una fuente de peligro y de miedo.

El poco conocimiento relativo a la gravedad de los efectos de los accidentes potenciales en El Beaterio produjo la reacción de las autoridades locales y estatales. En este contexto, se realizaron estudios de simulación de la amenaza tecnológica, los mismos que constituirían uno de los mecanismos para controlar las fuentes de peligro. Al mismo tiempo, estas simulaciones se vuelven argumentos importantes para las decisiones jurídico territoriales de mitigación de riesgos. Un primer estudio se realizó en 1993 bajo el encargo del MDMQ a la USAID (Agencia Internacional de Desarrollo de los Estados Unidos), con la colaboración de técnicos de la Agencia Norteamericana de Protección Ambiental (Usepa). Una de las conclusiones fue: en caso de una explosión (BLEVE —explosión originada por nubes de gas ardiente en desplazamiento-) en las instalaciones, se generaría un impacto en un radio aproximado de 650 metros. Por su lado, PETROCOMERCIAL encargó en 1992 al Instituto Mexicano de Petróleo (IMP) la realización de un estudio de amenaza tecnológica que definió para BLEVE un radio de impacto de 500 m (PETROECUADOR, 1994).

Estas dos formas de abordar el riesgo dejan en claro la incertidumbre relativa al radio de potenciales daños, pues dependiendo del modelo de simulación y

6 Según las 110 encuestas realizadas a la población en el año 2009 en los barrios situados dentro de los límites de los $500 \mathrm{~m}$ alrededor de las instalaciones de El Beaterio. 
los datos aplicados, este será de tamaño diferente. La delimitación de las zonas de impacto potencial recae en el campo político de la negociación. En este caso el MDMQ y PETROCOMERCIAL han considerado la información del IMP como oficial por el detalle de los análisis generados y los diferentes argumentos técnico industriales utilizados en un proceso de control de las fuentes de peligro. Esta herramienta es, sin duda, un punto referencial importante, pues hasta ese momento no se había realizado ningún estudio de simulación de accidentes tecnológicos vinculados a fuentes de peligro en áreas urbanas. Asimismo, un modelo técnico de ayuda a la decisión generó cambios en las políticas de planificación de uso de suelo en la zona (que hasta la década de 1980 era aún expansionista).

En efecto, uno de los primeros lineamientos de las políticas de planificación presentes en el Plan de Estructura Espacial Metropolitana, abordado en 1992, es el reconocimiento de una zona de protección de 500 m alrededor de las instalaciones de El Beaterio. Sin embargo, esta medida supone una prohibición de los asentamientos que se encontraban anteriormente en estos lugares, algunos de los cuales estaban en vías de legalización como los barrios San Blas, Caupicho o El Conde (Peralta et al., 1993). Con la adopción de las primeras medidas jurídico territoriales se reconocen los riesgos tecnológicos en el territorio. Esto supone la aparición de una amenaza potencial y una población expuesta, al mismo tiempo que genera fuertes conflictos políticos territoriales en los espacios de riesgo, en su mayoría relacionados con las formas ilegales de ocupación y las presiones de desplazamiento de El Beaterio.

Por otro lado, un factor importante en la concretización de los espacios de riesgo es el elevado crecimiento de la población iniciado desde la década de 1980. En efecto, al comparar las cartografías de uso real y planificado de 1996 con las de 1982 las distorsiones mayores sobresalen a través de un cambio drástico de uso de suelo de vocación agrícola a residencial en un periodo de 15 años (ver fig. 5). Estas áreas de crecimiento urbano han ido consolidándose bajo un esquema de desconocimiento del riesgo existente y de ventajas del precio del suelo muy atractivo para la población pobre e inmigrante de otras provincias del Ecuador. Aproximadamente el 73 \% de la población señala como primera ventaja de localización en la zona el bajo costo del suelo, ante otras ventajas como la accesibilidad o la poca contaminación ambiental (encuestas 2009)7.

La concretización y el reconocimiento de los espacios de riesgo suponen muchas contradicciones en la adaptabilidad de las herramientas de planificación a los usos reales establecidos. Efectivamente, los cambios de uso real del suelo obligan a menudo a realizar modificaciones en la planificación urbana adaptándose de esta forma a las condiciones de uso real para reducir los conflictos engendrados y así controlar las zonas urbanizadas con normas enfocadas a las formas de ocupación de suelo. No obstante, esta adaptabilidad se contradice con el manejo del riesgo tecnológico en el territorio cuando se define una zona de protección sobre parte de

7 Otros datos de las preferencias de localización señalan la cercanía a lugares de trabajo, vías de acceso, situación familiar o tranquilidad.

8 La concepción del término «proteger» implica resguardar a la población de un evento potencial. 


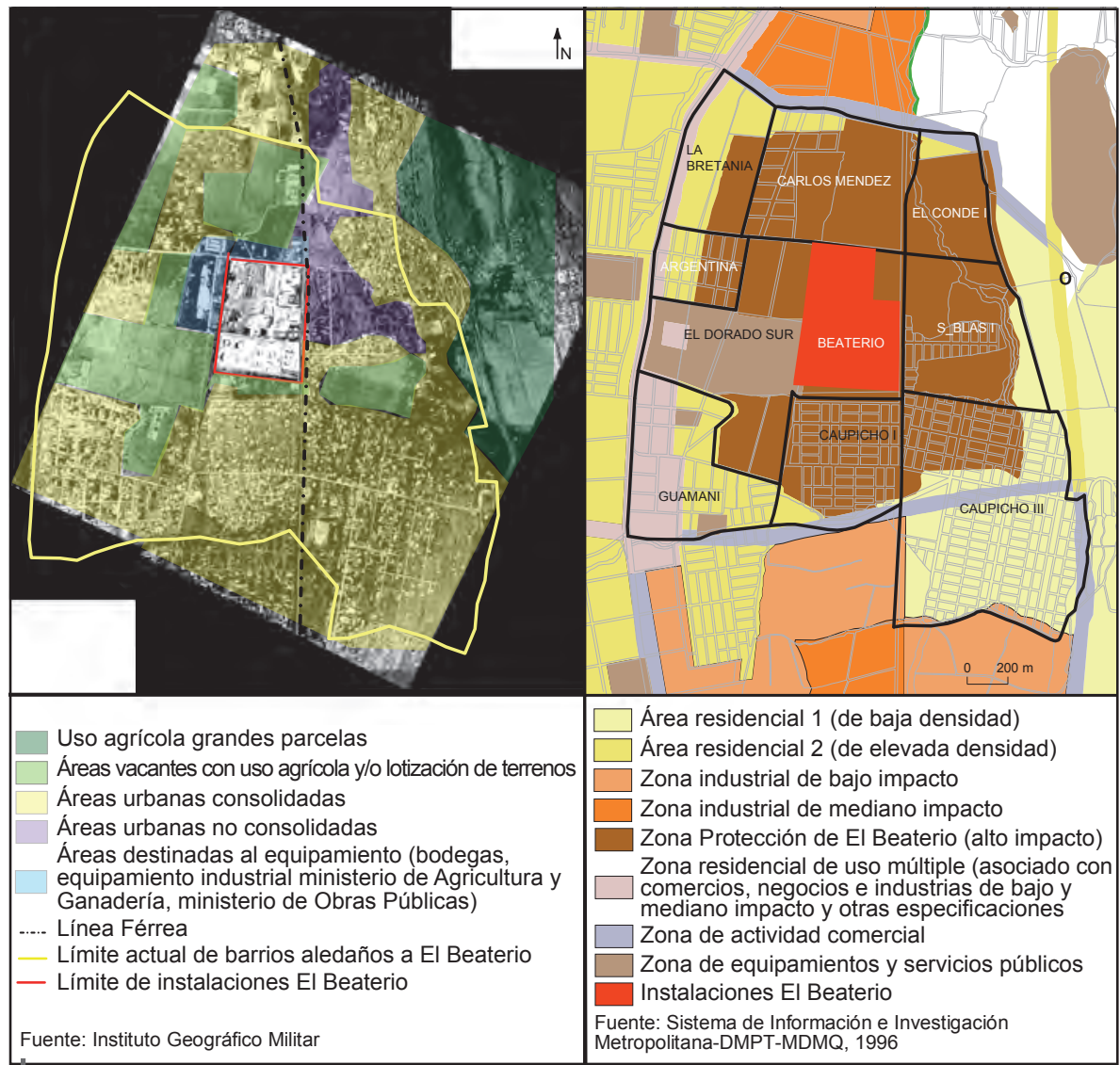

Figura 5 - Comparación de uso real (fotografías aéreas) y uso planificado de El Beaterio en el año 1996

las zonas que se encuentran ya urbanizadas o en consolidación, por la aplicación de las anteriores herramientas de planificación del mismo MDMQ (Plan Quito 1981). Esto crea una primera diferenciación territorial y de conflicto, la misma que ha sido analizada a través de un modelo espacial (corema) considerando la información de uso real y uso planificado obtenido de la Dirección de Planificación Territorial del MDMQ (fig. 6). El objetivo de este modelo es contrastar los dos usos para evidenciar principalmente distorsiones en cuanto a la construcción de los espacios de riesgos alrededor de la terminal El Beaterio. Los criterios de organización del espacio en el modelo se basaron en diferenciar áreas de reclusión o protección, de evolución urbana y de heterogeneidad de usos, así como ejes de atracción y espacios de disimetría expresados por la localización diferenciada de elementos urbanos importantes.

Uno de los primeros rasgos de diferenciación surge a través de la desaparición funcional de la línea férrea como un eje de crecimiento y dinámica importante 


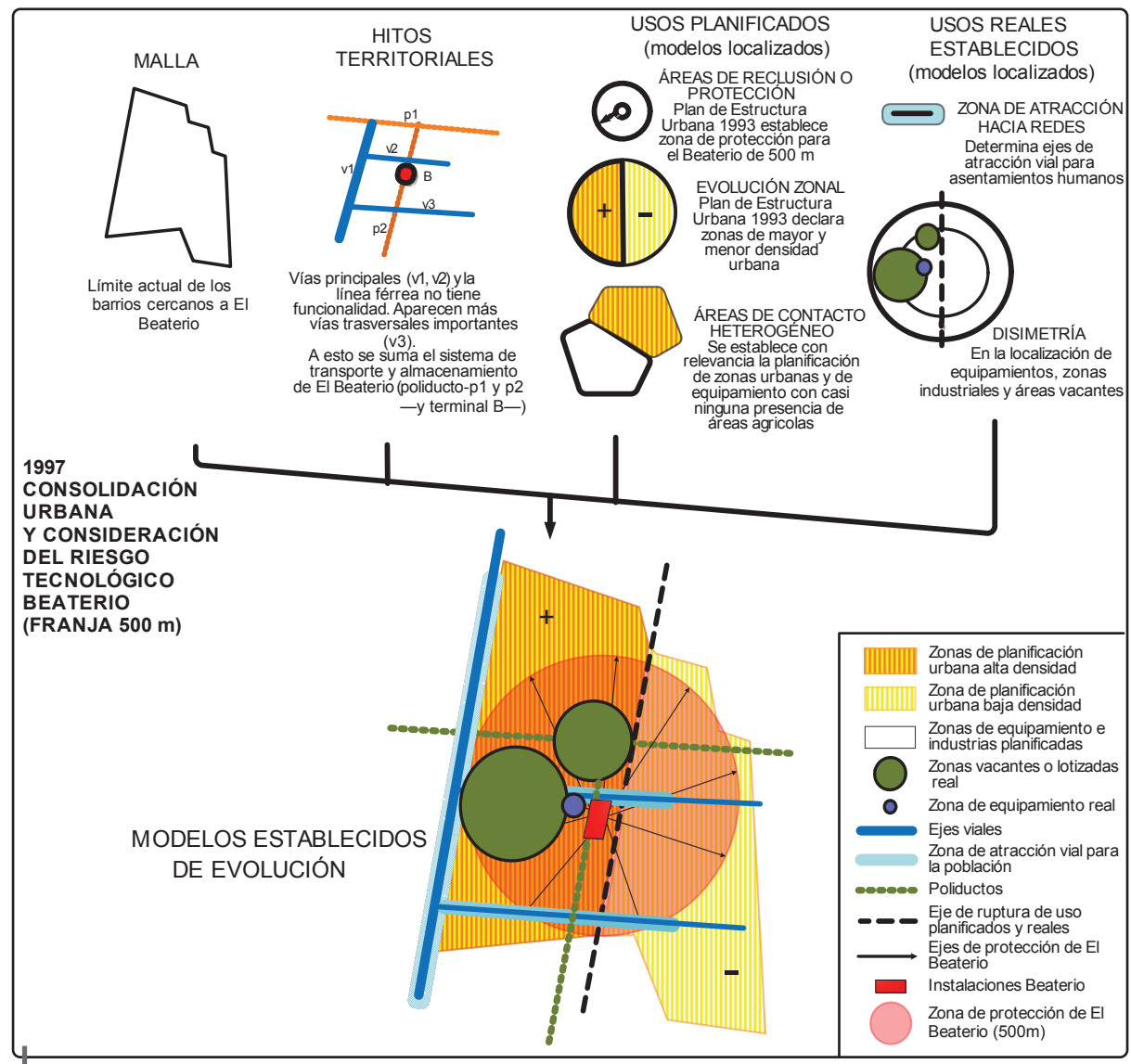

Figura 6 - Corema sobre la estructura urbana del sector de El Beaterio en 1997

hasta finales de la década de 1980. Otro rasgo se caracteriza por una disimetría encontrada entre los usos residenciales planificados de alta y baja densidad y la localización de grandes espacios vacantes o de lotización en la parte noroccidental y occidental de El Beaterio. Por otra parte, se propicia la localización industrial hacia el sur y norte de los límites de la zona de protección. Asimismo, la zona de 500 m cubre una vasta área que involucra diferentes barrios (Argentina, El Conde, San Blas, Caupicho, Franco Mendez, La Bretaña...) que en su mayoría corresponden a zonas urbanas consolidadas. Esto demuestra que la concretización y el reconocimiento de espacios de riesgo es, ante todo, un espacio de conflicto entre la ocupación poblacional efectiva y los usos planificados, y a la vez, un espacio de interés político territorial para reducirlo (Municipio del Distrito Metropolitano de Quito, 2005). La decisión de los límites territoriales de la zona de conflicto es una decisión política que depende del radio considerado de la amenaza tecnológica, apoyado sobre modelos basados en un razonamiento científico y técnico. 


\section{4. La transformación de los escenarios de riesgo de El Beaterio: la salida de las esferas de GLP}

El área de protección de El Beaterio es una medida correctiva que considera los potenciales efectos de un accidente. No obstante, considerando que la zona de protección no impidió la ocupación poblacional, surgió como alternativa la eliminación de fuentes de peligro. En efecto, a partir del año 1994, se emprenden acciones sobre las fuentes de peligro a través de la decisión política del MDMQ (resolución 027 de 1994) de desalojo de las mismas hacia la zona de Itulcachi (localizada en el valle oriental del DMQ, ver figura 1)9 como una medida de control definitivo de los riesgos tecnológicos.

Esta decisión de desalojo de instalaciones peligrosas con fines de eliminar una amenaza tecnológica del medio urbano es un hecho sin precedentes en el Ecuador. Este proceso, que duró aproximadamente 9 años (desde 1994 hasta el 2003 entre la decisión y el desplazamiento efectivo), dio lugar a muchas discusiones en el campo técnico, económico, político y territorial antes de tomar una decisión definitiva sobre su desplazamiento.

Finalmente, tras largos periodos de debate y de gran presión por parte de la población aledaña a las instalacionesio se logró desplazar una parte de la infraestructura industrial considerando solo las esferas de GLP como las más peligrosas por sus potenciales explosiones por BLEVE. La decisión de este traslado es considerado como un logro del consenso entre dos tipos de actores de diferentes escalas. En efecto, las instituciones estatales, como PETROECUADOR o el ministerio de Energía y Minas, consideran El Beaterio inamovible por constituir un lugar estratégico para la alimentación de combustible de la región centro norte. Al mismo tiempo, el MDMQ desea su desalojo pues es considerado como una fuente de peligro para la población circundante. En este contexto, se dieron diferentes escalas de interés del mismo lugar, en cuyos términos el desplazamiento del GLP fue considerado como la opción más viable por varios aspectos: la reducción de costos, las ventajas de reubicación, la reducción del peligro y por lo tanto del riesgo.

Sin embargo, ¿de qué forma se redujeron los riesgos con esta medida política de desplazamiento? ¿Permitió esta medida controlar el riesgo tecnológico en El Beaterio después de 9 años de gestión? De hecho, la salida de una parte de las instalaciones de El Beaterio tuvo consecuencias político jurídicas en el territorio que llevaron a una nueva transformación del riesgo.

9 Otra decisión pudo haber sido el desplazamiento de la población pero, políticamente, se decidió actuar sobre la reducción de la amenaza, al considerarla como la variable crucial en el manejo del riesgo por el peligro engendrado hacia 8 barrios de la zona.

10 Un conjunto de barrios del Sur (25 aproximadamente) se organizó para conformar el «Frente de Lucha de Los Barrios del Sur». Su misión: ejercer presión para la salida de El Beaterio. 


\section{5. Cambio de las franjas de seguridad: un primer elemento de transformación de la concepción del riesgo}

El primer elemento visible de la transformación de los espacios de riesgo operada por el desplazamiento de las esferas de gas GLP es la decisión jurídica de reducir la franja de protección de 500 a 100 m, argumentada por el menor peligro que representan los tanques de combustibles líquidos que aún permanecen en la zona (gasolina y diesel principalmente). Esta área de protección se basó en el modelamiento realizado sobre la radiación por fuego del IMP el año 1994, y ratificado por un estudio de riesgos realizado por PETROCOMERCIAL, tomando distancia desde el filo de cada tanque y determinando las radiaciones térmicas de ondas caloríficas de afectación en caso de incendio (diagrama de pétalos). Dicho estudio coincide con un radio de afectación de 100 metros.

La definición de una nueva zona de riesgo trajo consecuencias para la forma de planificar la zona. Según el PUOS 2006 (Programa de Uso y Ocupación del Suelo a cargo de la Dirección de Planificación Territorial del MDMQ), se establecen usos residenciales en su mayor parte de alta densidad, en las zonas que anteriormente correspondían a los $500 \mathrm{~m}$ de protección de El Beaterio (ver fig. 7). Esto es corroborado con la legalización de varios barrios como San Blas, Caupicho, El Conde y Francisco Méndez (Municipio del Distrito Metropolitano de Quito, 2006). Otro ejemplo es la asignación de una importante área vacante, localizada al norte de El Beaterio, para la construcción de un gran colegio municipal en el sur de Quito (en la figura 7 se puede apreciar su localización en la zona en morado que corresponde a «áreas de promoción», colindante a la zona de protección de El Beaterio). La proyección de esta nueva obra pone en evidencia un nuevo elemento de interés en la zona y un futuro hito que contribuiría aún más en la consolidación urbana, al mismo tiempo que ratifica la confianza en las medidas jurídico territoriales de control y dominio de riesgo.

Al observar la imagen satelital se evidencia una ocupación de la población en la parte oriental y sur de las instalaciones de El Beaterio, la misma que en un periodo de 10 años registró nuevos barrios ilegales denominados Jesús de Nazaret y Estela Maris, localizados en la nueva zona de protección de $100 \mathrm{~m}$. Con ello se inicia una nueva réplica de los espacios de riesgo en conflicto, manejadas en el año 1994, donde dos diferencias son notorias:

- La disminución de los límites de la zona de protección.

- La construcción de un colegio como un elemento de interés y de consolidación urbana (ver fig. 7).

Los asentamientos poblacionales en la zona de influencia de El Beaterio demuestran la adaptabilidad de las herramientas de planificación a los usos reales encontrados (ver fig. 8). En efecto, mientras los usos reales muestran que la mayor parte de la zona corresponde a un área urbana consolidada, el uso planificado define estas áreas de acuerdo a su densidad y con ello intenta manejar parámetros de ocupación del suelo ya iniciados desde el año 1994. 


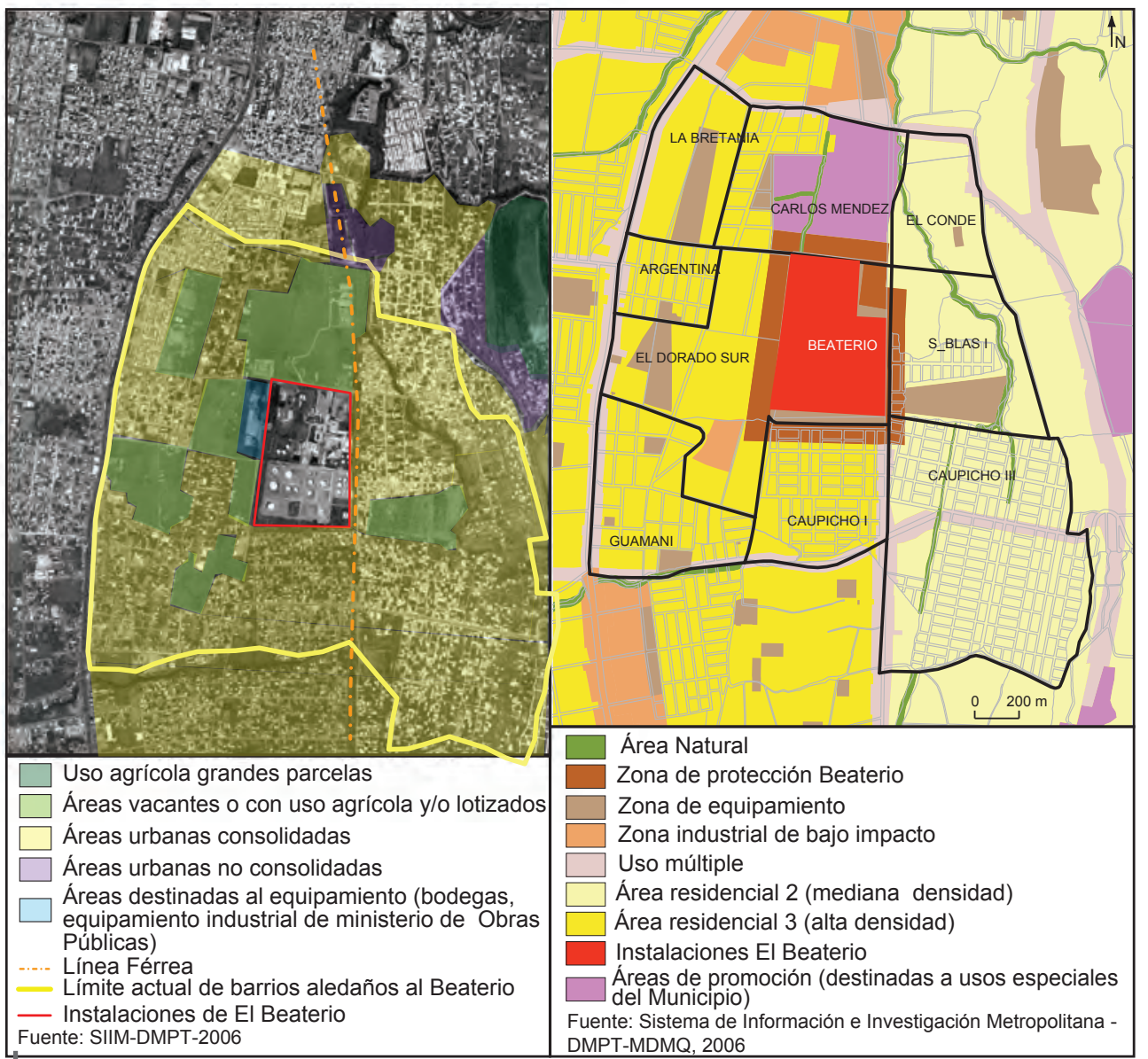

Figura 7 - Comparación de uso real (imagen satelital) y uso planificado de El Beaterio en el año 2006

En una observación general de toda la zona de influencia de El Beaterio, resalta la heterogeneidad entre espacios de mayor y menor densidad urbana.

Además existe el proyecto de consolidar sectores residenciales en las zonas vacantes, lo que ratificaría en un futuro el carácter eminentemente urbano de los sectores aledaños a las instalaciones El Beaterio (MDMQ, 2004). La distribución de zonas vacantes o lotizadas, en su mayoría localizadas en el occidente y sur de El Beaterio, se asemeja a la estructura urbana establecida en el año 1997. Es decir, al cabo de casi 10 años, la evolución urbana ha sido en apariencia menos rápida que en los años precedentes, en contraste con los espacios de riesgo, que se han transformado más rápidamente debido a los diversos factores político territoriales asumidos en cada administración municipal. 


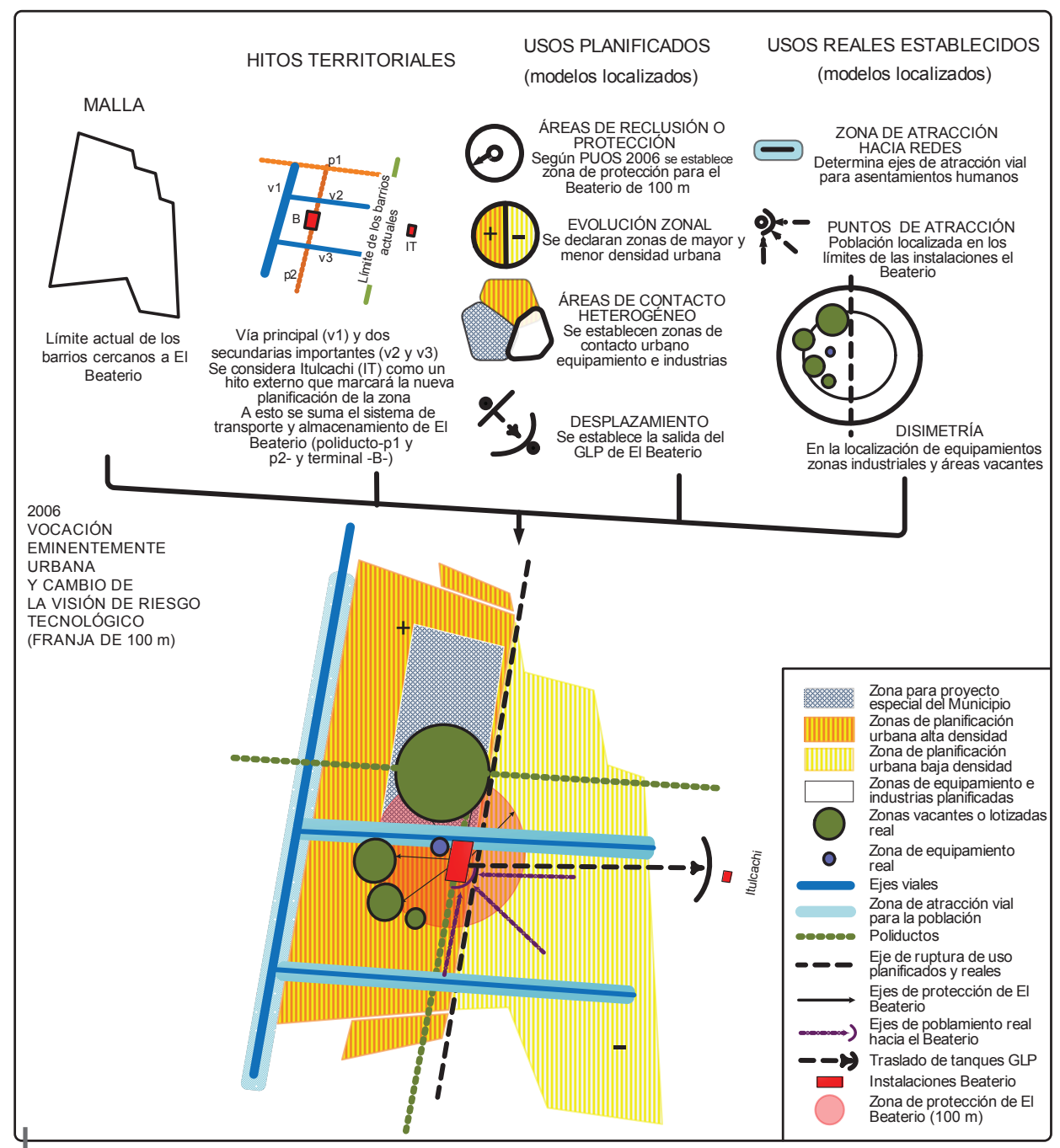

Figura 8 - Corema sobre la estructura urbana del sector de El Beaterio en 2006

En el corema de la figura 8, se evidencia una nueva organización territorial donde la planificación trata de adaptarse a las dinámicas existentes para después favorecer la transformación de los espacios de riesgo. Este hecho se evidencia tanto por la sostenibilidad de usos residenciales de alta densidad como por la construcción del colegio cercano a las instalaciones de El Beaterio (en la figura 8, su localización corresponde a la zona gris denominada «Zona de proyecto especial del Municipio»).

Por otro lado, la figura 8 muestra otra dinámica territorial importante, relacionada con el traslado de una parte del espacio de riesgo de El Beaterio hacia Itulcachi. Este hecho muestra el interés político de desplazar los riesgos hacia zonas periféricas. 


\section{DEBILIDADES EN LOS MODELOS DE RIESGO Y CAMBIO DE LA PERCEPCIÓN DE RIESGO POR PARTE DE AUTORIDADES Y POBLACIÓN: SEGUNDO FACTOR DE TRANSFORMACIÓN DE LOS ESPACIOS DE RIESGO}

La continuación y enfatización de los proyectos de consolidación urbana como el colegio municipal y los posibles cambios de uso de los suelos vacantes a usos residenciales fortalecen la idea de consolidación urbana y de control de riesgo. Efectivamente, la confianza de los actores tomadores de decisión correspondientes (MDMQ y PETROCOMERCIAL) sobre el control de los espacios de riesgo se basa en las herramientas de ayuda a la decisión obtenidas de los modelos de simulación tecnológica, que definen el alcance territorial de escenarios potenciales de accidentes. No obstante ila declaración de una zona de 100 m es suficiente para limitar las zonas de mayor riesgo tecnológico?

El uso de modelos para el análisis de accidentes potenciales a menudo considera la interacción de diversos factores de riesgo asociados a las fuentes de peligro; dependiendo del modelo en uso, algunos factores podrían tener más relevancia que otros (Botta, 2007). De esta manera, el uso de los modelos y sus resultados en términos de evaluación y cuantificación de consecuencias potenciales pueden variar. En efecto, muchos modelos de simulación de accidentes se basan en experiencias de eventos ocurridos y sus limitaciones radican en que no siempre se ajustan al análisis de nuevos eventos potenciales debido al desconocimiento de nuevos factores de riesgo o de la especificidad de estos. Así, un evento nuevo podría tener consecuencias de distinta naturaleza que no pueden ser apreciadas en función de accidentes pasados, lo que genera incertidumbre (Kouabénan \& Cadet, 2006).

En particular, la simulación de escenarios de accidentes como BLEVE (nube de gas ardiente en desplazamiento) o POOL FIRE (fuego producido por derrame de combustible en forma de charco) para combustibles, usualmente considera factores de riesgo internos a las instalaciones. Es el caso del modelo del IMP considerado para El Beaterio o del diagrama de pétalos, que consideran factores de riesgo basados en las propiedades químico físicas de los productos inflamables y las propiedades físicas de los lugares de almacenamiento. No se consideran factores de riesgo externos, como las condiciones meteorológicas, las barreras artificiales de obras civiles externas a las instalaciones, el tipo de terreno, la reacción del material de construcción de las casas o la combinación con otras amenazas como sismos o inundaciones. Esto difunde una visión determinista del riesgo (Zimmermann, 1996) que limita las condiciones de ocurrencia de un accidente tecnológico y presenta gran parcialidad en términos de consecuencias.

Por ello, una de las primeras dificultades de representación de los riesgos tecnológicos radica en la complejidad del sistema tecnológico y su concepción en términos de probabilidad de ocurrencia y consecuencia, adaptadas con la mayor precisión a la realidad (Zimermman et al., 2002). Por lo tanto, la simulación de los radios de afectación calorífica en El Beaterio representa una visión determinista 
con muchas limitaciones en el análisis de consecuencias. Si bien disminuyen las probabilidades de ocurrencia (seguridad industrial), aumenta la incertidumbre en términos de consecuencias potenciales.

Otras debilidades de los modelos de simulación se relacionan también con la incertidumbre de los radios del peligro simulados. Un ejemplo de ello es el accidente de Santa Rosa de Chillogallo ocurrido en el año 2003 en el sector sur de Quito. Un incendio de grandes proporciones se produjo por la rotura del poliducto Santo Domingo-Quito que transportaba gasolina. La concentración de gasolina, en un punto cercano al poliducto, debido a las condiciones de terreno produjo un incendio cuya onda de calor alcanzó unos $100 \mathrm{~m}$ a la redonda afectando unas veinte viviendas (según datos del Cuerpo de Bomberos de Quito), cuando está previsto en las Normas de Ocupación de Suelo del MDMQ, un retiro de seguridad de solamente 15 metros por cada lado11. Por lo tanto, las medidas políticas y jurídico territoriales de control de la amenaza son cuestionables y los umbrales de seguridad sujetos a incertidumbres.

Una segunda reflexión se enfoca en las distorsiones en la escala de acciones de reducción de riesgo por parte de la población entre los dos estados de transformación de riesgo. Efectivamente, al comparar las acciones de reducción de riesgos desde mediados de la década de 1990 hasta el desplazamiento de una parte de las instalaciones en 2003, éstas eran más constantes y demandaron incluso una organización de barrios (Frente de Lucha de Barrios del Sur), con el fin de ejercer más fuerza y presión en el cierre de El Beaterio. No obstante, con la salida de los tanques de GPL de El Beaterio, este Frente de Lucha dejó de existir y aproximadamente el $61 \%$ de las personas que habitan en los alrededores (correspondientes a los 500 m de protección) perciben una desaparición de los conflictos con PETROCOMERCIAL generados por la situación de riesgo (algunos mantienen un conflicto relacionado con la presencia de obras o problemas de movilidad de los camiones cisternas). No obstante, el $39 \%$ señala que existen conflictos en cuanto a la legalización y reubicación de sus propiedades, en especial en aquellos barrios localizados dentro de los 100 m del área de protección. Este 39 \% señala además conflictos relacionados con factores de contaminación por olores, residuos sólidos o ruido de tanqueros, así como problemas puntuales relacionados con los riesgos de transporte de combustibles por parte de los camiones cisternas.

Ciertamente, el desplazamiento del GLP generó una cierta tranquilidad en la población. No obstante, un 62 \% piensa que si bien el riesgo disminuyó aún existen peligros relacionados con el almacenamiento de combustibles líquidos 12. Estos resultados confirman que la población aún percibe un riesgo en la zona. No obstante, un 59 \% piensa que no es necesario un cambio de vivienda para

11 Más detalles pueden encontrase en el articulo «El incendio del 17 de abril del 2003 en Chillogallo (Quito)» en el presente volumen, pp. 527-543.

12 El $62 \%$ de la población menciona que, con el desplazamiento de las bombonas de GLP, el peligro no desapareció sino que disminuyó o se redujo drásticamente. Al contrario, un 38 \% menciona que se eliminó el riesgo pues el gas era lo más peligroso. 
sitios más seguros, en contraposición de un 39 \% que sí lo desearía pero bajo condiciones particulares de legalidad y de presencia de infraestructuras urbanas y de servicios. Por lo tanto, un gran porcentaje de la población asimila el riesgo pero es indiferente en cuanto a sus efectos potenciales.

Por un lado, esta pasividad actual de la población define un nuevo estado de vulnerabilidad relacionado con la percepción de riesgo en la zona. Es decir, en cierta manera existe una asimilación de un riesgo aceptable (Douglas, 1996) a pesar de sus potenciales efectos peligrosos. Esta tendencia de aceptabilidad del riesgo en la población es muy contraria a aquella sostenida en la década de 1990 y principios del 2000, donde se asimilaban los efectos del riesgo como una posibilidad a la catástrofe y de acción inmediata.

En consecuencia, el resultado de la salida de las esferas de GLP de El Beaterio produjo un cambio de percepción de la población en cuanto a los efectos potenciales del riesgo, lo cual demuestra que aún coexiste la idea del peligro pero sus consecuencias son muy diferentes.

Por otro lado, el aumento de la vulnerabilidad en la población no solo se enfoca a la percepción sino a los niveles de organización y gestión del riesgo. El 76 \% de la población no participa en ninguna actividad relacionada con la reducción de riesgo en la zona, mientras el 12 \% señala acciones relacionadas con actividades de capacitación y charlas organizadas por instituciones operativas como bomberos o relaciones comunitarias de PETROCOMERCIAL. Solo el $8 \%$ señala haber emprendido alguna acción como planes de prevención, alarmas comunitarias y control de material contra incendio pero muy parcialmente.

Con los argumentos dados, se puede concluir que la salida del GLP disminuyó la capacidad reactiva y proactiva de la población, al mismo tiempo que redujo la intensidad y la probabilidad del riesgo, generando como consecuencia un nuevo estado de incertidumbre relativo al riesgo tecnológico. Esta evidencia se basa en las políticas de consolidación urbana y, al mismo tiempo, de control de la amenaza tecnológica. En efecto, las políticas de urbanización de la zona se refuerzan a partir de la idea de control de los espacios de riesgo reducidos a una zona de protección de 100 m, a pesar de las debilidades de los modelos de simulación. Por otro lado, a nivel de consecuencias, las fotografías muestran un aumento de la población alrededor de las instalaciones de El Beaterio. A esto se suma el aumento de la vulnerabilidad de la población debido a la percepción de indiferencia mostrada en relación con los efectos potenciales del peligro y de la ausencia de acciones de reducción de riesgos que anteriormente existían con la presencia de las esferas de GLP. 


\section{CONCLUSIONES}

Como aspectos importantes se puede resaltar los siguientes puntos:

\section{Un fortalecimiento de las vulnerabilidades relacionadas con la población}

Un primer aspecto de la vulnerabilidad se relaciona con la exposición de la población a los riesgos tecnológicos. El proceso de crecimiento y consolidación urbana alrededor de las instalaciones de El Beaterio se inicia hace aproximadamente 30 años y son apoyadas por decisiones políticas expansionistas de la propia municipalidad. A esto se suma el bajo costo del suelo como un factor socioeconómico principal de atracción para los asentamientos humanos.

Actualmente las tendencias de crecimiento y consolidación urbana de los asentamientos dentro y fuera de los 100 m crearían nuevos espacios de exposición al riesgo en caso de producirse un accidente más allá de esta zona de protección.

Otro aspecto relacionado con la vulnerabilidad son los factores de percepción del riesgo. Como se ha analizado, el efecto del desplazamiento de las esferas de gas supuso una disminución de la intensidad y de la probabilidad de ocurrencia de accidentes en El Beaterio pero, al mismo tiempo, produjo un sentimiento de aceptación del riesgo tecnológico relacionado con sus efectos potenciales.

Otros factores de la vulnerabilidad se relacionan con los niveles de organización, gestión y preparación ante un desastre de la población para reducir los riesgos. En efecto, la aceptabilidad del riesgo en la zona incide en la pasividad de la población para enfrentar los riesgos aún existentes. Por ejemplo, no existe una estructura barrial que realice una gestión para reducir los riesgos como existía antes de la salida de las esferas de gas en el año 2004. Asimismo, las acciones de prevención y preparación son muy escasas.

\section{Una planificación municipal que, de cierta manera, planifica el riesgo}

La formación y transformación de los espacios de riesgo en la zona de El Beaterio son producto de un proceso de evolución territorial y social ejercido principalmente a través de medidas políticas y jurídicas a lo largo del tiempo. El proceso de construcción del riesgo de la zona de El Beaterio fue apoyado por los sucesivos planes de manejo territorial establecidos por el MDMQ, los mismos que presentaban una visión de desarrollo urbano y carecían de la visión de riesgo.

De hecho, en una primera instancia las instalaciones de El Beaterio son más percibidas como fuentes económicas que como peligro. A partir del año 1993, con la primera decisión jurídico territorial del Municipio, existe el reconocimiento de las fuentes de peligro y con ello la concretización de un espacio de riesgo a 
través de la conformación de una franja de protección de 500 m alrededor de las instalaciones. Estos límites se definieron a partir de estudios de simulación de accidentes potenciales. En el periodo 1994-2003 se inicia acciones sostenibles para el control de los espacios de riesgos tecnológicos, a partir de la reducción de la probabilidad/intensidad de las amenazas de las fuentes de peligro. Esto se concretizó con el traslado de una parte importante del peligro de El Beaterio (esferas de gas GLP). Paralelamente, el espacio de riesgo reconocido fue reducido a una estrecha franja de protección de 100 m circunscribiendo las instalaciones aún permanentes en la zona (tanques de combustible líquido principalmente).

En este contexto, se puede apreciar el proceso de construcción tecnocrática del riesgo tecnológico en el marco de políticas de planificación territorial; al mismo tiempo refleja los esfuerzos políticos y jurídicos realizados por el MDMQ para controlar los riesgos tecnológicos en El Beaterio, los mismos que simplemente se transforman (ver fig. 9).

1981

PRIMERA FORMA DE PLANIFICACION DEL RIESGO
1993

SEGUNDA FORMA DE PLANIFICACION DEL RIESGO
2004

TERCERA FORMA DE PLANIFICACION DEL RIESGO

Fuente: DMPT-MDMQ-2009

Elaboración: Jairo Estacio

Figura 9 - Principales etapas de planificación del riesgo tecnológico alrededor de la terminal El Beaterio

\section{Aumento de riesgo a pesar de una disminución de la amenaza tecnológica}

Las acciones de la Municipalidad se han concentrado mayoritariamente en el control de la amenaza tecnológica y no en el control de la urbanización que se desarrolla en zonas aledañas a El Beaterio. Desde este punto de vista, el riesgo ha aumentado debido al incremento de la vulnerabilidad de la población expuesta y por la incertidumbre de las herramientas de ayuda a la decisión. En efecto, las decisiones municipales emprendidas sobre la consolidación de espacios urbanos toman como referencia un radio de 100 m de protección definido por 
los estudios de simulación de la amenaza tecnológica. No obstante, los radios de peligro obtenidos de estos modelos de simulación se basan en principios deterministas para definir la intensidad de los accidentes potenciales, olvidándose de las interacciones posibles con las condiciones exteriores. Por lo tanto, el límite de la zona de protección actual debería ser considerado como referencial. Sin embargo, la Municipalidad, a contracorriente, ha optado por la consolidación urbana de los barrios fuera de la franja de 100 m de protección sin las previsiones técnicas para la reducción de riesgos tecnológicos. Esto además se evidencia con la construcción de nuevos elementos de interés como el proyecto del nuevo Colegio Municipal del Sur de Quito, uno de los establecimientos educativos más grandes del sur de Quito.

Por otro lado, la baja frecuencia de accidentes menores y la ausencia de accidentes mayores relacionados a este tipo de instalaciones en el Ecuador, limitan la validez de los datos para un manejo estadístico y probabilístico de las zonas en cuanto a evaluar las posibles consecuencias de un accidente tecnológico (Godard et al., 2002). Bajo este punto de vista, las zonas de riesgo propuestas carecen de referentes estadísticos de accidentabilidad que permitan ajustar criterios más exactos y reales en su concepción.

\section{¿Qué hacer para reducir los espacios de riesgos y la incertidumbre?}

La reducción de los riesgos no solo radica en el control de los espacios de riesgo sino en el control de las urbanizaciones alrededor de las fuentes de peligro. Este aspecto se relaciona con el control de los espacios de riesgo en conflicto (población dentro de los 100 m de riesgo) y también con la generación de medidas correctivas y extensivas hacia zonas localizadas fuera de los límites de los $100 \mathrm{~m}$. En este caso se requiere el mejoramiento de las estrategias de planificación urbana considerando los riesgos tecnológicos en estas zonas. Esto implica asumir las incertidumbres dentro de las decisiones de control de urbanizaciones considerando que la intensidad de los accidentes puede variar en función de características particulares. En tales términos, es importante prever políticas de control urbano que integren la noción de riesgos tecnológicos en la zona. Esto requiere medidas preventivas en las formas de construcción y ocupación de suelo basándose no solo en características demográficas de las zonas sino también en la consideración de espacios de riesgo de mayor amplitud. El conjunto de estrategias y medidas deberían ser incorporadas a través de herramientas de planificación preventiva de riesgos tecnológicos para instalaciones de alto peligro13.

Por otra parte, se requiere conformar un dispositivo de preparación y prevención para la población considerando el rol de diversos actores que toman decisiones

13 Experiencias como el PPRT en Francia (Planes de Prevención de Riesgos Tecnológicos de Francia a cargo del ministerio de la Ecología, del Desarrollo y Ordenamiento sostenible) definen estrategias de reducción de riesgos basadas en un principio integral de reducir al máximo los peligros en la fuente, de control de uso y ocupación urbana que incluso incluyen medidas de expropiación de zonas de riesgo. 
(Municipio, PETROECUADOR) así como organismos operativos y población. Esto permitiría reducir las consecuencias de accidentes potenciales en las zonas aledañas a El Beaterio.

Otra de las medidas territoriales recae en la negociación, expropiación y reubicación de la población localizada en los espacios de riesgo en conflicto. Estas medidas han sido emprendidas por la Municipalidad y PETROCOMERCIAL, pues resulta más económico desplazar los barrios ilegales localizados en las franjas de seguridad que trasladar las propias instalaciones. Este proceso garantiza guardar la franja sin ocupación y por lo tanto, reducir las consecuencias en los espacios de riesgo en conflicto.

\section{Referencias citadas}

BOTTA, N., 2007 - Teorías y Modelos de Accidentes. Factor de riesgo: Una Visión Actualizada sobre la Seguridad, n. ${ }^{\circ}$ 3: 30 pp.; Santa Fe-Argentina.

BRUNET, R., 2000 - Des modèles en géographie ? Sens d'une recherche. Bulletin de la Société de Géographie de Liège, n. ${ }^{\circ}$ 2: 21-30. Conferencia dictada el 24 de noviembre de 1999.

DOUGLAS, M., 1996 - La aceptabilidad del riesgo según las ciencias sociales, 173 pp.; Barcelona, España: Ediciones Paidos Studio.

ENRIQUEZ, F., 2005 - La dinámica industrial y productiva de Quito; Quito: MDMQ, CONQUITO. Documento inédito.

GODARD, O., HENRY, C., LAGADEC, P. \& KERJAN, E., 2002 - Traité des nouveaux risques, 620 pp.; París: Éditions Gallimard. Coll Folio/Actuel.

KOUABENAN, D. R. \& CADET, B. (ed.), 2006 - Psychologie du risque : identifier, évaluer, prévenir, 352 pp.; Nantes-France: De Boeck.

MDMQ, 2004 - Plan Equinoccio 21. Quito hacia el 2025. Documento ciudadano; QuitoEcuador.

MUNICIPALIDAD DE QUITO, 1967 - Plan Director de Urbanismo de San Franscisco de Quito, 42 pp.; Quito-Ecuador: MDMQ. Memoria del Plan.

MUNICIPIO DE QUITO, 1974 - Quito y su Área Metropolitana: «Plan Director 1973-1993», 103 pp.; Quito-Ecuador: Dirección de Planificación.

MUNICIPIO DE QUITO, 1980 - Plan Director de Quito, 75 pp.; Quito-Ecuador: Dirección de Planificación. Documento no publicado.

MUNICIPIO DISTRITO METROPOLITANO DE QUITO, 2005 - Legislación y normativa para la gestión de suelo en el DMQ, 341 pp.; Quito-Ecuador: Dirección Metropolitana de Territorio y Vivienda.

MUNICIPIO DISTRITO METROPOLITANO DE QUITO, 2006 - Plan General de Desarrollo Territorial DMQ: 2000 a 2020, 92 pp.; Quito-Ecuador: Dirección Metropolitana de Planificación Territorial.

PERALTA, E. \& BORJA, K., 1993 - Quito Área Metropolitana, 120 pp.; Quito-Ecuador: MDMQ-Dirección General de Planificación. «Planificación y Urbanismo», Colección Quito. 
PÉREZ, G., 1984 - Esquema Director Plan Quito; Quito-Ecuador: Municipio de Quito, Dirección de Planificación.

PETROECUADOR, 1994 - Análisis de riesgo para la determinación de la Franja de Seguridad de la Terminal de Almacenamiento y Distribución de productos limpios y gas LP El Beaterio, 290 pp.; Quito-Ecuador: IMP, Volumen 1.

ZIMMERMANN, P., RAVANEL, L. \& SAINT-GERAND, T., 2002 - Cartographie des risques technologiques majeurs : Nouvelles expectatives avec les SIG. Collection Mappemonde, $\mathbf{n}^{\circ}$ 65: 17-21.

ZIMMERMANN, P., 1996 - De I'usage de la cartographie dans l'appréhension des RTM; Revue de Géographie de Lyon, Vol. 71, n. ${ }^{\circ}$ 1: 11-16. Número temático: «Risques et pollutions industriels et urbains» (Donze, ed.). 